\title{
Modeling and Optimization of Membrane Process for Salinity Gradient Energy Production
}

\author{
Lianfa Song
}

Citation: Song, L. Modeling and Optimization of Membrane Process for Salinity Gradient Energy Production. Separations 2021, 8, 64 . https://doi.org/10.3390/ separations 8050064

Academic Editor: Mingheng Li

Received: 21 April 2021

Accepted: 6 May 2021

Published: 12 May 2021

Publisher's Note: MDPI stays neutral with regard to jurisdictional claims in published maps and institutional affiliations.

Copyright: (C) 2021 by the author. Licensee MDPI, Basel, Switzerland. This article is an open access article distributed under the terms and conditions of the Creative Commons Attribution (CC BY) license (https:/ / creativecommons.org/licenses/by/ $4.0 /)$.
Department of Civil, Environmental, Construction Engineering, Texas Tech University, Lubbock, TX 79409, USA; lianfa.song@ttu.edu; Tel.: +1-806-834-4356

\begin{abstract}
When hydraulic pressure was added on the feed side of the membrane in the otherwise conventional pressure retarded osmosis (PRO) process, the production rate of the salinity gradient energy could be significantly increased by manipulating the hydraulic pressures on both sides of the membrane. With hydraulic pressure added on the feed side of the membrane, much higher water flux could be obtained than that under the osmotic pressure of the same value. The osmotic pressure of the draw solution, instead of drawing water through the membrane, was mainly reserved to increase the hydraulic pressure of the permeate. In this way, orders of magnitude higher power density than that in the conventional PRO can be obtained with the same salinity gradient. At the optimal conditions, it was demonstrated that the energy production rates that were much higher than the economical breakeven point could be obtained from the pair of seawater and freshwater with the currently available semipermeable membranes.
\end{abstract}

Keywords: salinity gradient energy; pressure retarded osmosis; hydraulic pressure; semipermeable membrane; optimization

\section{Introduction}

Water and energy systems are interdependent and must be tackled together as a waterenergy nexus in modern society $[1,2]$. The development of technologies to recover the dissipated energy embodied in water is one major focus in the R\&D in water-energy nexus. Besides the well-known kinetic power of water resulted from hydraulic head difference, salinity gradient energy (SGE) is a type of less known energy embodied in water due to the chemical potential between different salinities [3-5]. When two solutions of different salinities are separated with a semipermeable membrane, water moves through the membrane from the low salinity side to the high salinity side, driven by this chemical potential [6-8]. The chemical potential can be harnessed with a membrane process commonly known as pressure retarded osmosis (PRO). The amount of SGE is estimated at about 2.6 terawatts globally or approximately $20 \%$ of the current worldwide energy consumption rate [9].

The SGE has not been utilized yet mainly because of the low efficiency of the PRO process $[10,11]$. All pilot PRO processes conducted so far failed to continuously produce power at a rate above 5 watts per square meter of the membrane, which is the economic breakeven point for harnessing SGE estimated according to the current membrane cost and electricity price [12-16]. A recent study suggested that water continuity inside the membrane is critical for water transport through the membrane and that it might not be maintained under osmotic pressure [17]. The addition of external hydraulic pressure on the feed side may help to maintain water continuity inside the membrane so that the water flux and, therefore, the power production rate could be significantly increased [18]. Independent studies reported a similar role of hydraulic pressure on water flux in pressure-assisted osmosis (PAO) $[19,20]$.

The main objective of this paper is to present a theoretical investigation about the impact of hydraulic pressures on the energy production rate. Equations for the power 
production rate with hydraulic pressure applied on both sides of the membrane are formulated, and the optimal condition for SGE harnessing is derived. The suitability of currently available membranes and plausible scenarios for profitable operation of the membrane process are also discussed and identified.

\section{Power Production Calculation}

The membrane process under consideration is schematically shown in Figure 1. A flow cell is divided into a draw chamber and feed chamber with a semipermeable membrane. The freshwater of negligible osmotic pressure is fed into the feed chamber at a flow rate $Q_{1}$ under the hydraulic pressure of $P_{E}$. The seawater of osmotic pressure $\Delta \pi$ is circulated through the draw chamber at a flow rate $Q_{2}$ under hydraulic pressure of $P_{R}\left(>P_{E}\right)$. The freshwater permeates through the membrane into the draw chamber and acquires the higher hydraulic pressure. The flow out of the draw chamber is split into two streams. One stream of flow rate $Q_{2}$ goes to the pressure exchanger to pass the pressure to the incoming seawater and then is discharged. The other stream of flow rate $Q_{1}$ is used to turn the hydro-turbine to produce mechanical or electrical energy. The hydraulic pressures on feed side and draw side will be referred as the "external pressure" and "retarded pressures" from now on, respectively.

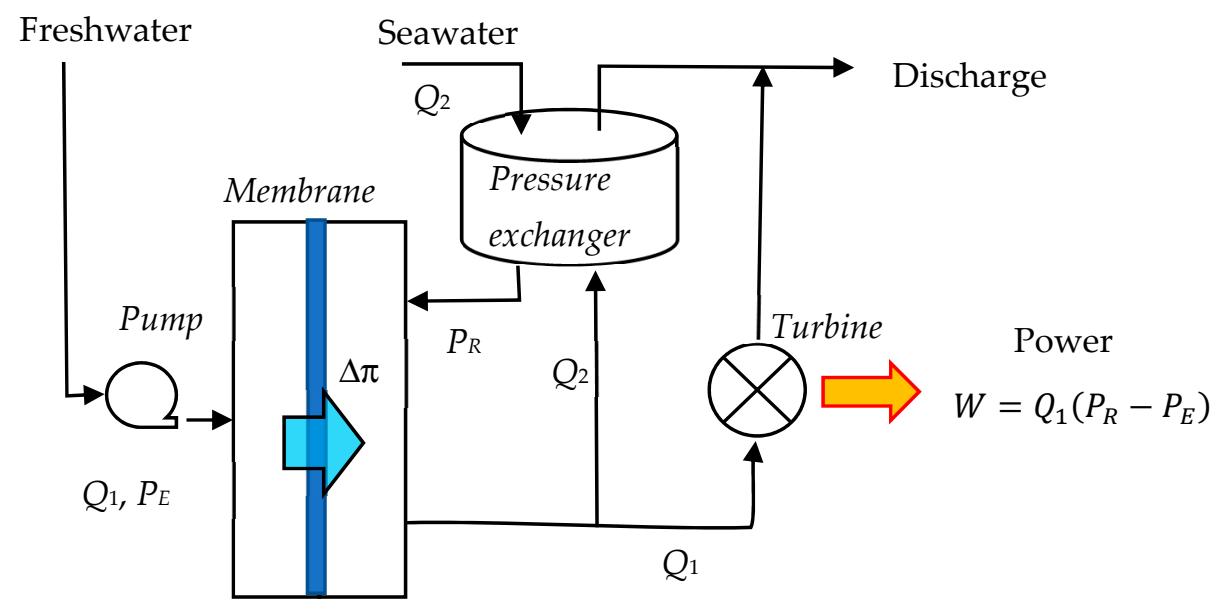

Figure 1. Schematic of the membrane process for harnessing SGE. The freshwater and the seawater enter the membrane chambers under hydraulic pressures $P_{E}$ and $P_{R}\left(>P_{E}\right)$, respectively.

When both external and retarded hydraulic pressures are simultaneously applied to a membrane with a higher osmotic pressure of the draw solution, water flux across the membrane can be calculated with [18]:

$$
J=A\left[\left(1-\lambda_{0}\right) e^{-\alpha\left(\Delta \pi-P_{R}\right)}\left(\Delta \pi-P_{R}\right)+P_{E}\right]
$$

where $J$ is the water flux; $A$ is the water permeability of the membrane; $\lambda_{0}$ is the initial fraction of the membrane area blocked by air/vapor bubbles; $\alpha$ is the cavitation coefficient; $\Delta \pi$ is the osmotic pressure of the draw solution; $P_{R}$ and $P_{E}$ are the retarded pressure and external pressure, respectively. The cavitation coefficient is a parameter to characterize the membrane process for cavitation, which can be a function of water quality, membrane material property, and other characters of the membrane process. The expression before the net osmotic pressure $\Delta \pi-P_{R}$ reflects the negative impact of the breakdown of water continuity on water flux. It can be seen from Equation (1) that the external hydraulic pressure $P_{E}$ is more effective on driving the water across the membrane because it is unaffected by the breakdown of water continuity. Experimental supports to this claim were reported previously in the literature [18-20].

There is no energy consumption in conventional PRO, and the feed water is not pressurized. In the membrane process shown in Figure 1, energy is spent to drive water 
across the membrane because of the external pressure applied to the feed water. Therefore, the net energy production rate per membrane area should be calculated by

$$
W=W_{\text {out }}-W_{\text {in }}=J P_{R}-J P_{E}=J\left(P_{R}-P_{E}\right)
$$

where $W$ is the power density of the membrane, and $W_{i n}$ and $W_{\text {out }}$ are the power input and output per unit membrane area, respectively. In general, the retarded hydraulic pressure should be smaller than, or at the most equal to, the osmotic pressure of the draw solution so that the draw side of the membrane is favorable for water to enter from the feed side. Equation (2) indicates that net energy will be produced as long as the external pressure is smaller than the retarded pressure, i.e., $P_{E}<P_{R} \leq \Delta \pi$.

\section{Process Optimization}

Equation (2) shows that the power density of the membrane for a given salinity gradient (e.g., between seawater and freshwater) is a function of the external and retarded pressures. In this section, the external and retarded pressure that maximize power density of the membrane will be studied. This will be done in two steps. The first step is to optimize the external pressure with a fixed retarded pressure. Combining Equations (1) and (2), the power density of the membrane can be written as

$$
W=A_{o}\left(\Delta \pi-P_{R}\right)\left(P_{R}-P_{E}\right)+A_{h} P_{E}\left(P_{R}-P_{E}\right)
$$

where $A_{o}\left(=A\left(1-\lambda_{0}\right) e^{-\alpha\left(\Delta \pi-P_{R}\right)}\right)$ is the permeability under osmotic pressure, and $A_{h}(=A)$ is the permeability under hydraulic pressure. The first term and the second term on the righthand side of Equation (3) are the power densities generated by water fluxes resulting from the net osmotic pressure and the external pressure, respectively.

Since the osmotic pressure $\Delta \pi$ and the retarded pressure $P_{R}$ are fixed, $A_{o}$ is, therefore, a constant. Letting the derivative of $W$ in Equation (3) with respect to $P_{E}$ equal to zero, i.e.,

$$
\frac{\partial W}{\partial P_{e}}=A_{h} P_{R}+A_{o} P_{R}-2 A_{h} P_{E}-A_{o} \Delta \pi=0,
$$

the external hydraulic pressure that maximizes the power density can be determined as

$$
P_{E}=\frac{P_{R}}{2}-\frac{A_{o}}{2 A_{h}}\left(\Delta \pi-P_{R}\right)
$$

Substituting Equation (4) into Equation (3) results in

$$
W=\frac{A_{h}}{4}\left[\left(1-\lambda_{0}\right) e^{-\alpha\left(\Delta \pi-P_{R}\right)}\left(\Delta \pi-P_{R}\right)+P_{R}\right]^{2}
$$

Equation (5) is the maximum power density of the membrane when the osmotic pressure of the draw solution and the retarded pressure on the draw side are specified.

The second step is to use Equation (5) to find the optimal $P_{R}$ that maximizes the power density of the membrane for a given osmotic pressure of the draw solution. Similarly, the derivative of $W$ in Equation (5) with respect to $P_{R}$ can be determined as

$$
\frac{d W}{d P_{R}}=\frac{A_{h}}{2}\left[\left(1-\lambda_{0}\right) e^{-\alpha\left(\Delta \pi-P_{R}\right)}\left(\Delta \pi-P_{R}\right)+P_{R}\right]\left\{\left(1-\lambda_{0}\right) e^{-\alpha\left(\Delta \pi-P_{R}\right)}\left[\alpha\left(\Delta \pi-P_{R}\right)-1\right]+1\right\}
$$

The derivative in the above equation equals zero only when

$$
\left(1-\lambda_{0}\right) e^{-\alpha\left(\Delta \pi-P_{R}\right)}\left[\alpha\left(\Delta \pi-P_{R}\right)-1\right]+1=0
$$


Rearranging the equation results in:

$$
P_{R}=\Delta \pi-\frac{1}{\alpha}\left[1-\frac{e^{\alpha\left(\Delta \pi-P_{R}\right)}}{1-\lambda_{0}}\right]
$$

Since the value of the term in the square brackets is always negative, the retarded pressure $P_{R}$ that would maximize power density is greater than the osmotic pressure $\Delta \pi$, which is out of pressure range. It means that the maximum power density of the membrane must occur at the endpoints of the domain, 0 or $\Delta \pi$.

The maximal power density cannot occur at the endpoint $P_{R}=0$ because there is no power is produced at this point. Therefore, the retarded pressure that maximizes the power density must be the osmotic pressure of the draw solution, i.e.,

$$
P_{R}=\Delta \pi
$$

Substituting Equation (7) into Equation (4) resulting in

$$
P_{E}=\frac{P_{R}}{2}=\frac{\Delta \pi}{2}
$$

Substituting Equations (7) and (8) into Equation (3), the maximum power density of the membrane is

$$
W=\frac{1}{4} A_{h} \Delta \pi^{2}
$$

Equation (9) is the maximum power density that is achieved at the external pressure of $\Delta \pi / 2$ and retarded pressure of $\Delta \pi$, respectively.

Recall that the power density of the membrane in the conventional PRO is:

$$
W=\frac{1}{4} A_{0} \Delta \pi^{2}
$$

The only difference between Equation (9) and Equation (10) is that the hydraulic permeability is used in the former and the osmotic permeability in the latter.

\section{Simulations and Discussion}

The power density of the membrane process shown in Figure 1 was simulated below and compared with the conventional PRO. In all of the simulations, seawater and freshwater of negligible osmotic pressure were considered as draw and feed solutions. It is worthy to point out that Equation (3) is for the energy production in ideal situations. The losses due to the concentration polarization and other inefficiencies of the membrane process are not considered. Furthermore, the efficiencies of the pressure exchanger and pumps in the system are assumed to be ideally $100 \%$. In real-world situations, a lower energy production rate would be expected because of non-ideality of the membrane systems.

\subsection{High Power Density of Membrane}

The hydraulic permeability and osmotic permeability of a membrane are needed to calculate the power density of the membrane. The hydraulic permeability of the membranes can be obtained from the manufacturers' data sheets or the reported values in the literature. The typical permeability of $3.6 \mathrm{~L} / \mathrm{m}^{2} \cdot \mathrm{h} \cdot$ bar for brackish water $\mathrm{RO}$ membranes was used in this study for the calculation of the water flux under hydraulic pressure. The osmotic permeability of the membranes is usually not directly available. However, studies have demonstrated that the osmotic permeability can be determined by multiplying the hydraulic permeability with a factor involving the structural parameter by

$$
A_{o}=A e^{-S J / D}
$$


where $S$ is the structural parameter, and $D$ is diffusion coefficient of salt. The ratio of the osmotic permeability to the hydraulic permeability is $A_{o} / A=e^{-S J / D}$. The ratios for different permeate fluxes and structural parameters were calculated and listed in Table 1. It can be seen that the osmotic permeability is much smaller than the hydraulic permeability for $\mathrm{RO}$ membranes because its structural parameter is usually much greater than $1 \mathrm{~mm}$ [21,22]. To be conservative, a relatively large value of $1 / 10$ will be used for the ratio of the osmotic permeability to the hydraulic permeability in the following discussion.

Table 1. The ratio of hydraulic permeability to osmotic permeability (i.e., $e^{-S J / D}$ ) *.

\begin{tabular}{ccccc}
\hline \multirow{2}{*}{$\begin{array}{c}\text { Water Flux } \\
\boldsymbol{J}(\boldsymbol{\mu \mathbf { m }} / \mathbf{s})\end{array}$} & $\mathbf{1 0 . 0 0}$ & $\mathbf{5 . 0 0}$ & $\mathbf{1 . 0 0}$ & $\mathbf{0 . 5 0}$ \\
\cline { 2 - 5 } & $6.76 \times 10^{-6}$ & $2.60 \times 10^{-3}$ & $3.04 \times 10^{-1}$ & $5.51 \times 10^{-1}$ \\
2.00 & $1.76 \times 10^{-8}$ & $1.33 \times 10^{-4}$ & $1.68 \times 10^{-1}$ & $4.09 \times 10^{-1}$ \\
3.00 & $4.57 \times 10^{-11}$ & $6.76 \times 10^{-6}$ & $9.25 \times 10^{-2}$ & $3.04 \times 10^{-1}$ \\
4.00 & $1.19 \times 10^{-13}$ & $3.45 \times 10^{-7}$ & $5.10 \times 10^{-2}$ & $2.26 \times 10^{-1}$ \\
5.00 & $3.09 \times 10^{-16}$ & $1.76 \times 10^{-8}$ & $2.81 \times 10^{-2}$ & $1.68 \times 10^{-1}$ \\
6.00 & &
\end{tabular}

* The diffusion coefficient of sodium chloride $\left(D=1.68 \times 10^{-9} \mathrm{~m}^{2} / \mathrm{s}\right)$ was used in the calculation.

The power density of the membrane calculated with Equation (3) is graphically presented in Figure 2. The osmotic pressure of the seawater is calculated to be 29.16 bar with the van't Hoff equation at a temperature of $20{ }^{\circ} \mathrm{C}$ by assuming the seawater as the sodium chloride solution. Generally, the peak power density of the membrane increases monotonically with the increasing retarded hydraulic pressure $P_{R}$. Both the maximum power densities $W^{*} P R O$ of the conventional PRO and $W^{*}$ New of the membrane with external pressure are indicated in the figure. $W^{*} P R O$ occurs at $P_{R}=0.5 \Delta \pi$ and $P_{E}=0$ while $W^{*}$ New at $P_{R}=\Delta \pi$ and $P_{E}=0.5 \Delta \pi$. It is obvious that the maximum power density of the membrane with external pressure is much higher than that of conventional PRO.

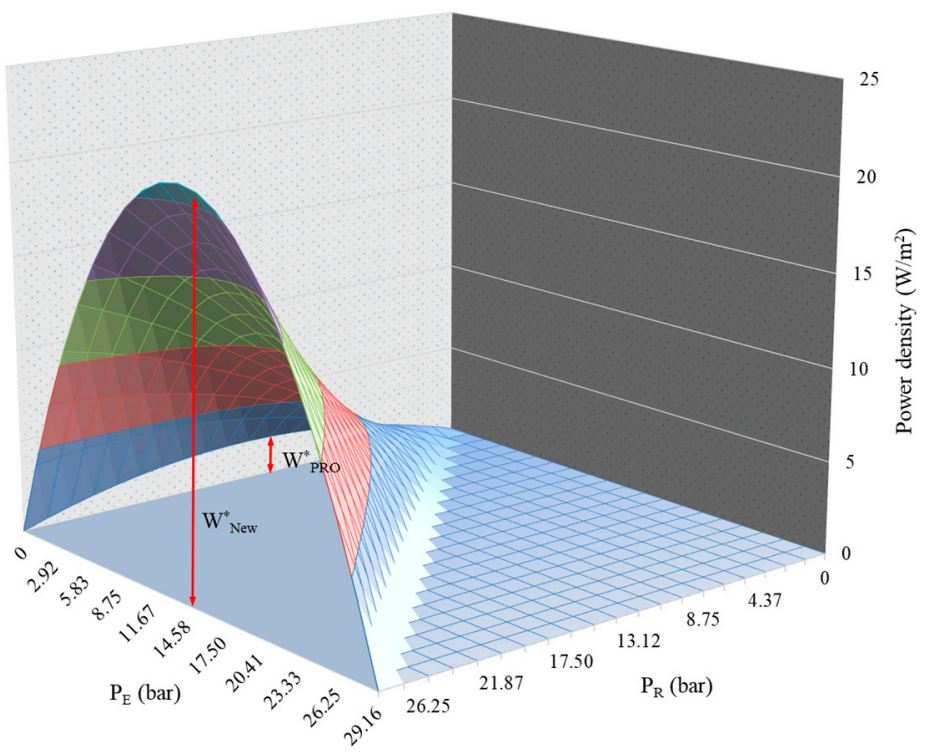

Figure 2. Power density of the membrane as a function of the retarded and external hydraulic pressures.

Instead of the 3D diagram, the power densities of the membrane for the same salinity gradient between seawater and freshwater are presented in Figure 3 as a function of the external pressure for a series of the retarded pressures. The retarded pressures as fractions of the osmotic pressure of the draw solution are indicated on the figure. The curves show that the power density of the membrane with external pressure increases with the increasing retarded pressure. The maximum power density of the membrane $\left(\sim 21 \mathrm{~W} / \mathrm{m}^{2}\right)$ occurs at $P_{R}=\Delta \pi$ and $P_{E}=0.5 \Delta \pi$. The power density of the membrane in the conventional 
$\mathrm{PRO}$ as a function of the retarded pressure is also presented on the figure by the broken line. The peak power density with external pressure is higher than $5 \mathrm{~W} / \mathrm{m}^{2}$ for $P_{R} \geq 0.5 \Delta \pi$, while the maximum power density in the conventional PRO is less than $2.2 \mathrm{~W} / \mathrm{m}^{2}$ with the same membrane and the same salinity gradient.

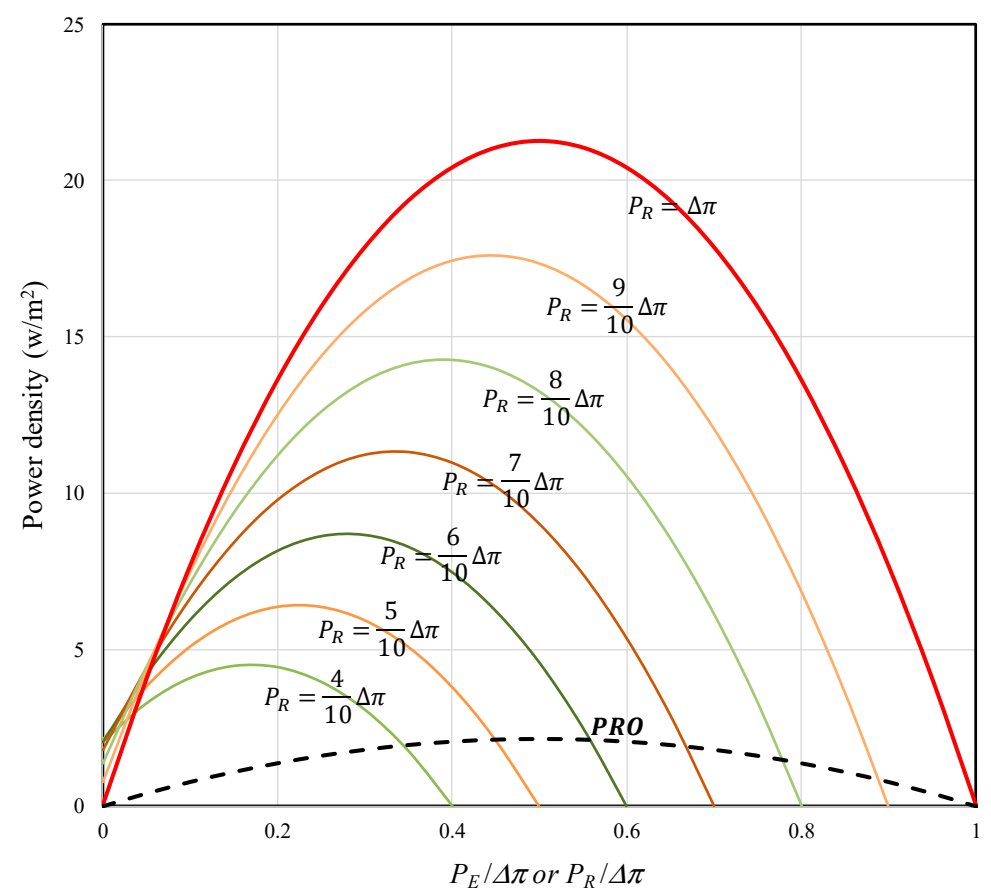

Figure 3. The power density of the membrane as a function of the external hydraulic pressure for various retarded pressures. The broken line is the curve for the conventional PRO as a function of the retarded pressure.

\subsection{Assessments of the Currently Available Membranes}

Membranes of the desirable properties are considered the key component for the successful harnessing of SGE in the conventional PRO. It was concluded at the shutdown of Statcraft pilot PRO project that such membranes would not become available in the foreseeable future [16]. However, the membranes are no longer a problem with addition of the external hydraulic pressure as the primary driving force for water transport.

The currently available semipermeable membranes are mainly $\mathrm{RO}$ membranes that can be roughly categorized into three groups: seawater $\mathrm{RO}$, brackish water $\mathrm{RO}$, and ultralow pressure RO (SWRO, BWRO, and ULPRO). These three groups of RO membranes have distinguishably different permeabilities. The peak power densities of these membranes with seawater and freshwater under the optimal arrangement of external and retarded pressures were calculated, and the results are shown in Table 2 together with their typical permeabilities.

Table 2. Peak power density of various membranes.

\begin{tabular}{cccc}
\hline Membrane & SWRO & BWRO & ULPRO \\
\hline Permeability, $\mathrm{L} / \mathrm{m}^{2} \cdot \mathrm{h} \cdot \mathrm{bar}$ & 1.0 & 3.6 & 10 \\
\hline Power density, $\mathrm{W} / \mathrm{m}^{2}$ & 5.91 & 21.26 & 59.06 \\
\hline
\end{tabular}

It can be seen that the breakeven power density of $5 \mathrm{~W} / \mathrm{m}^{2}$ can be achieved even with the least permeable SWRO membranes under the salinity gradient of seawater and freshwater. The power densities of BWRO and ULPRO membranes are markedly high at 21.26 and $59.06 \mathrm{~W} / \mathrm{m}^{2}$, respectively. It should be pointed out that the $\mathrm{RO}$ membranes possess more than sufficient mechanical strength that would be needed for harnessing SGE. 
In the above calculations, the original osmotic pressure of the seawater was used. Therefore, the values listed in Table 1 are actually the theoretical upper limits of the power density when an infinitesimal fraction of freshwater is mixed with seawater. In real-world situations, the osmotic pressure of the mixed solution should be smaller than the original osmotic pressure of seawater because a definite fraction of freshwater will mix with seawater. Substituting the osmotic pressure of the mixed solution into Equation (9), the equation becomes

$$
W=\frac{1}{4} A_{h}(1-f)^{2} \Delta \pi^{2}
$$

where $f\left(=V_{f} /\left(V_{f}+V_{d}\right)\right.$, with $V_{f}$ and $V_{d}$ being the volumes of feed water and draw solution, respectively, is the feed fraction to the membrane process.

Power density at different feed fractions was calculated for the three types of RO membranes, and the results are presented in Figure 4 . The broken line in the figure indicates the breakeven power density of $5 \mathrm{~W} / \mathrm{m}^{2}$. First, it can be seen that the power density of the membrane is a strong function of the feed fraction and that it decreases with the increasing feed fraction. Second, there is a range of feed fractions for each membrane in which above the breakeven power density of $5 \mathrm{~W} / \mathrm{m}^{2}$ can be obtained. Figure 4 shows that the SWRO membranes are practically unsuitable for harnessing SGE because they can only produce the required power density $\left(>5 \mathrm{~W} / \mathrm{m}^{2}\right)$ in a very small range of feed fractions, which is too small to be of any practical interests. The BWRO and ULPRO membranes are very promising candidates because they can produce the above breakeven point power density in ranges of feed fractions $0-50 \%$ and $0-70 \%$, respectively.

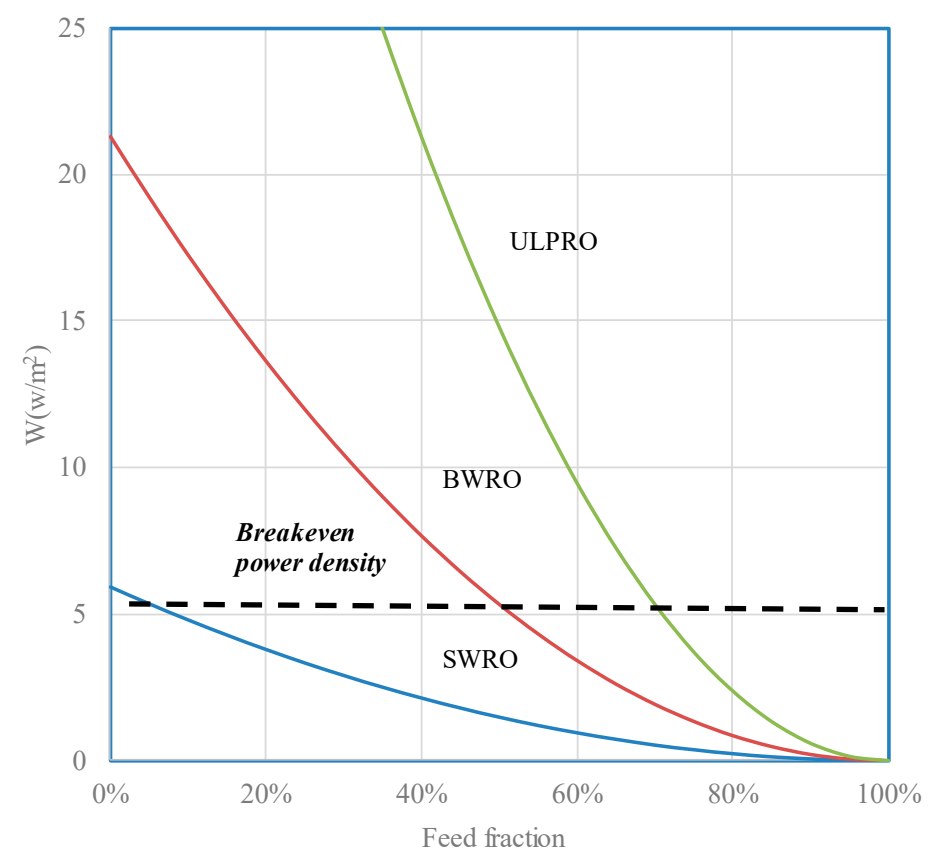

Figure 4. Power densities of typical SWRO, BWRO, and ULPRO membranes as functions of the feed fraction. The broken line indicates the economical breakeven point for harnessing SGE.

\subsection{Specific Energy}

Besides the power density of the membrane, the specific energy of water is another important parameter for successfully harnessing SGE [23-25]. Specific energy of water is defined as the energy extracted per unit volume of water processed. A necessary condition for profitably harnessing SGE is that the energy generated is greater than that consumed for pumping and pretreatment of the feed water and draw solution. Zhang et al. [25] derived a general expression to calculate the specific energy of water for cases in which the pretreatment costs are different for the draw solution and the feed water. The original 
expression was derived for feed water of a certain salinity. Therefore, it was first modified to suit the current case of feed water of negligible salinity as

$$
\hat{E}=\frac{\Delta \pi(1-f) \ln \left(\frac{1}{(1-f)}\right)}{f+\left(p_{d} / p_{f}\right)(1-f)}
$$

where $\hat{E}$ is the specific energy, and $p_{d}$ and $p_{f}$ are the pretreatment costs for draw solution and feed water, respectively.

The specific energy of water for different ratios of pretreatment costs for draw solution and feed water were calculated, and the results are presented in Figure 5. The ratios of the pretreatment costs are indicated in the figure. The broken line indicates the limiting case in which there is no cost involved for pretreatment of the draw solution. It can be seen that when the pretreatment cost ratio $P_{d} / P_{f}$ is around 0.40 , the peak specific energy of water is approximately $0.40 \mathrm{kWh} / \mathrm{m}^{3}$ at the feed fraction of about 0.5 . O'Toole et al. [26] and Altaee et al. [11] recently reported that the pretreatment cost for the river water was estimated to be $0.0665 \mathrm{kWh} / \mathrm{m}^{3}$ and $0.15 \mathrm{kWh} / \mathrm{m}^{3}$, respectively. Both research groups overestimated pretreatment costs of seawater for SGE production because the costs referred to were for desalination. Because seawater is the draw solution that moves away from the membrane, it is reasonable to assume a lower requirement for seawater for harnessing SGE than for desalination. When pretreatment cost for the seawater is lower or comparable to that for freshwater, net energy can be produced from the salinity gradient between seawater and river water.

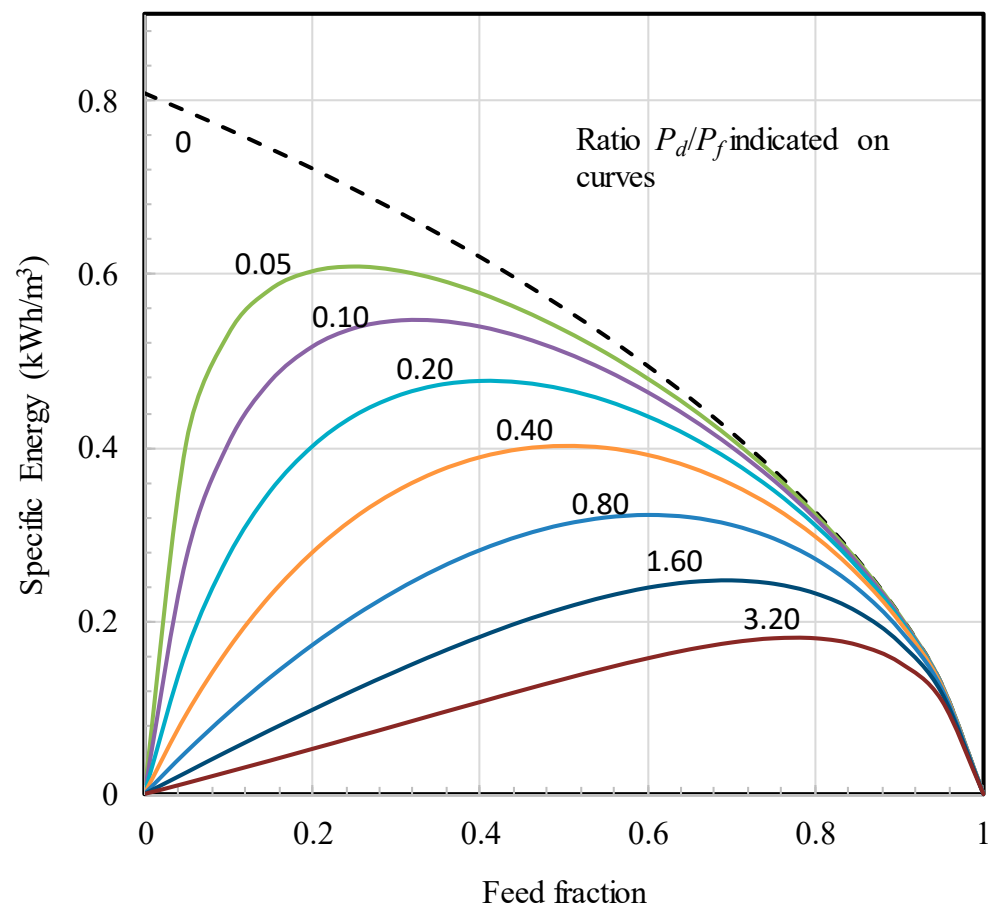

Figure 5. The specific energy of water as a function of the feed fraction. The broken line indicates the limiting specific energy for the zero pretreatment cost of seawater.

Inspecting Figures 4 and 5 together, it can be found that there is a plausible range of feed fraction around 0.5 , in which both power density of membrane and specific energy of water are favorable for profitably harnessing SGE between seawater and freshwater. Particularly, it also suggests that currently available BWRO and ULPRO membranes may provide the needed properties for harnessing SGE profitably. 


\section{Conclusions}

By manipulating hydraulic pressures on feed and draw sides of the membrane, a much higher production rate of SGE than that in the conventional PRO can be obtained. In this process, the chemical potential (in terms of osmotic pressure difference) from the salinity gradient is primarily used to raise the pressure of the permeated water. Under the external hydraulic pressure, water flux can be orders of magnitude higher than the direct use of osmotic pressure of the same value as the driving force. Therefore, the power density of the membrane can be orders of magnitude higher than in the conventional PRO.

Furthermore, the currently available BWRO and ULPRO membranes are capable to produce the power density above the breakeven point required for profitably harnessing the SGE between seawater and freshwater. These membranes also have the needed mechanical strength to work under the hydraulic pressure difference across the membrane at the optimal operation conditions. It has also been shown that the specific energy of water also satisfies the requirements for profitable harnessing SGE in a plausible range of feed fraction around 0.50 .

Funding: This research received no external funding.

Institutional Review Board Statement: Not applicable.

Conflicts of Interest: The authors declare no conflict of interest.

\section{References}

1. Hamiche, A.M.; Stambouli, A.B.; Flazi, S. A review of the water-energy nexus. Renew. Sustain. Energy Rev. 2016, 65, 319-331. [CrossRef]

2. DOE. Water Energy Nexus Executive Summary. Available online: https://www.energy.gov/downloads/water-energy-nexuschallenges-and-opportunities (accessed on 6 June 2019).

3. Wick, G.L.; Isaacs, J.D. Salt domes: Is there more energy available from their salt than from their oil? Science 1978, 199 , $1436-1437$. [CrossRef] [PubMed]

4. Mehta, G.D.; Loeb, S. Internal polarization in the porous substructure of a semipermeable membrane under pressure-retarded osmosis. J. Membr. Sci. 1978, 4, 261-265. [CrossRef]

5. Lee, K.L.; Baker, R.W.; Lonsdale, H.K. Membranes for power generation by pressure-retarded osmosis. J. Membr. Sci. 1981, 8, 141-171. [CrossRef]

6. Dandeno, J.B. Osmotic theories, with special reference to van't Hoff's law. Bull. Torrey Bot. Club 1909, 36, 283-298. [CrossRef]

7. Kahlenberg, L. On the nature of the process of osmosis and osmotic pressure with observations concerning dialysis. J. Phys. Chem. 1906, 10, 141-209. [CrossRef]

8. Yates, F.E. Osmosis: A transport of confusion. Am. J. Physiol. 1978, 235, R1. [CrossRef]

9. Post, J.W.; Veerman, J.; Hamelers, H.V.M.; Euverink, G.J.W.; Metz, S.J.; Nymeijer, K.; Buisman, C.J.N. Salinity-gradient power: Evaluation of pressure-retarded osmosis and reverse electrodialysis. J. Membr. Sci. 2007, 288, 218-230. [CrossRef]

10. Straub, P.; Deshmukh, A.; Elimelech, M. Pressure-retarded osmosis for power generation from salinity gradients: Is it viable? Energy Environ. Sci. 2016, 9, 31-48. [CrossRef]

11. Altaee, A.; Zhou, J.; Alanezi, A.A.; Zaragoza, G. Pressure retarded osmosis process for power generation: Feasibility, energy balance and controlling parameters. Appl. Energy 2017, 206, 303-311. [CrossRef]

12. She, Q.; Jin, X.; Tang, C.Y. Osmotic power production from salinity gradient resource by pressure retarded osmosis: Effects of operating conditions and reverse solute diffusion. J. Membr. Sci. 2012, 401-402, 262-273. [CrossRef]

13. Altaee, A.; Sharif, A. Pressure retarded osmosis: Advancement in the process applications for power generation and desalination. Desalination 2015, 356, 31-46. [CrossRef]

14. Gerstandt, K.; Peinemann, K.V.; Skilhagen, S.E.; Thorsen, T.; Holt, T. Membrane processes in energy supply for an osmotic power plant. Desalination 2008, 224, 64-70. [CrossRef]

15. Han, G.; Zhang, S.; Li, X.; Chung, T.S. High performance thin film composite pressure retarded osmosis (PRO) membranes for renewable salinity-gradient energy generation. J. Membr. Sci. 2013, 440, 108-121. [CrossRef]

16. Patel, S. Statkraft Shelves Osmotic Power Project. Available online: https://www.powermag.com/statkraft-shelves-osmoticpower-project/ (accessed on 9 September 2019).

17. Zhang, H.; Wang, J.; Rainwater, K.; Song, L. Metastable state of water and performance of osmotically driven membrane processes. Membranes 2019, 9, 43. [CrossRef]

18. Gao, N.; Wang, J.; Song, L. Independence of hydraulic pressures on the feed and draw solutions in the osmotically driven membrane processes. J. Membr. Sci. 2019, 586, 1-6. [CrossRef] 
19. Blandin, G.; Myat, D.T.; Verliefde, A.R.D.; Le-Clech, P. Pressure assisted osmosis using nanofiltration membranes (PAO-NF): Towards higher efficiency osmotic processes. J. Membr. Sci. 2017, 533, 250-260. [CrossRef]

20. Kim, B.; Gwak, G.; Hong, S. Analysis of enhancing water flux and reducing reverse solute flux in pressure assisted forward osmosis process. Desalination 2017, 421, 61-71. [CrossRef]

21. Klayson, C.; Cath, T.Y.; Deoyydt, T.; Vankelecom, I.F.J. Forward and pressure retarded osmosis: Potential solutions for global challenges in energy and water supply. Chem. Soc. Rev. 2013, 42, 6959-6989. [CrossRef]

22. Shaffer, D.L.; Werber, J.R.; Jaramillo, H.; Lin, S.; Elimelech, M. Forward osmosis: Where are we now? Desalination 2015, 356, 271-284. [CrossRef]

23. Lin, S.; Straub, A.P.; Elimelech, M. Thermodynamic limits of extractable energy by pressure retarded osmosis. Energy Environ. Sci. 2014, 7, 2706-2714. [CrossRef]

24. Straub, A.P.; Lin, S.; Elimelech, M. Module-Scale Analysis of Pressure Retarded Osmosis: Performance Limitations and Implications for Full-Scale Operation. Environ. Sci. Technol. 2014, 48, 12435-12444. [CrossRef] [PubMed]

25. Zhang, H.; Yang, W.; Rainwater, K.; Song, L. Limiting extractable energy from pressure retarded osmosis with different pretreatment costs for feed and draw solutions. J. Membr. Sci. 2017, 544, 208-212. [CrossRef]

26. O'Toole, G.; Jones, L.; Coutinho, C. River-to-sea pressure retarded osmosis: Resource utilization in a full-scale facility. Desalination 2016, 389, 39-51. [CrossRef] 